\title{
An ice-shelf model test based on the Ross Ice Shelf, Antarctica
}

\author{
D. R. MACAYEAL, \\ Department of the Geophysical Sciences, The University of Chicago, Chicago, IL 60637, U.S.A. \\ V. ROMMELAere, \\ Laboratoire de Glaciologie et Géophysique de l'Environnement, 38402 Saint-Martin-d'Hères Cedex, France \\ P. HuYBRECHTS, \\ Alfred-Wegener-Institut für Polar- und Meeresforschung, Postfach 120161, D-27515 Bremerhaven, Germany \\ C. L. Hulbe, \\ Department of the Geophysical Sciences, The University of Chicago, Chicago, IL 60637, U.S.A. \\ J. Determann, \\ Alfred-Wegener-Institute für Polar- und Meeresforschung, Postfach 120161, D-27515 Bremerhaven, Germany \\ C. RiTZ \\ Laboratoire de Glaciologie et Géophysique de l'Environnement, 38402 Saint Martin d'Hères Cedex, France
}

\begin{abstract}
A standard numerical experiment featuring the Ross Ice Shelf, Antarctica, is presented as a test package for the development and intercomparison of ice-shelf models. The emphasis of this package is solution of stress-equilibrium equations for an ice-shelf velocity consistent with present observations. As a demonstration, we compare five independently developed ice-shelf models based on finite-difference and finite-element methods. Our results suggest that there is little difference between finite-element and finite-difference methods in capturing the basic, large-scale flow features of the ice shelf. We additionally show that the fit between model and observed velocity depends strongly on the ice-shelf temperature field, for which there is presently little observational control. The main differences between model results are due to the equations being solved, the boundary conditions at the ice front and the discretization method (finite element vs finite difference).
\end{abstract}

\section{INTRODUGTION}

The character of ice-shelf modelling is distinctive in three important ways. First, problems studied with ice-shelf models tend to emphasize flow dynamics and comparison with observed flow fields as model-performance measures. This emphasis is motivated by the availability of field observations and by the fact that a well-accepted statement of the governing equations, boundary conditions and constitutive equations is yet to be established. Secondly, ice-shelf models must contend with the ocean and its effect on the basal melting rate. This effect has a direct role in the time-dependent mass balance part of iceshelf modelling. It also has an indirect influence because the temperature field of ice shelves is strongly influenced by basal melting. In many ways, the difficulty of measuring, or predicting from first principles, a basal melting rate is comparable to that of measuring or predicting a basal sliding velocity in a grounded ice sheet.
Thirdly, ice-shelf models must contend with two technical obstacles. The stress-balance equation which governs iceshelf flow is non-local, i.e. is elliptic in the two horizontal dimensions, and the mass-balance equation is not diffusive, i.e. is hyperbolic, and is thus capable of propagating shocks. These obstacles put stringent demands on the numerical methods applied in ice-shelf models and greatly complicate efforts to couple ice-shelf models with models of inland ice sheets (e.g. Huybrechts, 1990).

The participants of the 1994 EISMINT modelintercomparison workshop held in Bremerhaven decided that ice-shelf model validation and intercomparison coulc' be simplified if a standard test could be developed whic! separately considered the solution of the elliptic stres . balance equations apart from all other consideratior ; such as the mass balance. Here we present a standard ic eshelf model test which accomplishes this goal. For realism, and to assess ice-shelf model performance under condi- 
tions similar to actual research applications, we have based the test on the Ross Ice Shelf, Antarctica. Intercomparison of five independently developed ice-shelf models presented here illustrates the effects of spatial resolution (e.g. variable resolution in finite-element methods vs uniform resolution in finite-difference methods) and of the form of model equations and boundary conditions (e.g. treatment of the ice-front boundary condition).

\section{NOTATION}

\begin{tabular}{|c|c|}
\hline$\dot{A}$ & Snow-accumulation rate $\left(\mathrm{m} \mathrm{a}^{-1}\right)$ \\
\hline $\bar{B}$ & $\begin{array}{l}\text { Vertically averaged flow-law rate } \\
\text { constant }\left(\mathrm{Pa} \mathrm{s}^{\frac{1}{3}}\right)\end{array}$ \\
\hline$\delta_{i}$ & Mask variable $(0$ or 1$)$ \\
\hline & Strain-rate tensor $\left(\mathrm{s}^{-1}\right)$ \\
\hline & Gravitational acceleration $\left(9.81 \mathrm{~m} \mathrm{~s}^{-2}\right)$ \\
\hline$h$ & Observed ice thickness (m) \\
\hline$[H]$ & Characteristic vertical scale $\left(10^{3} \mathrm{~m}\right)$ \\
\hline$[L]$ & Characteristic horizontal scale $\left(10^{4} \mathrm{~m}\right)$ \\
\hline$\nu$ & Effective viscosity (Pas) \\
\hline$n$ & Flow-law exponent \\
\hline $\mathbf{n}$ & $\begin{array}{l}\text { Outward-pointing unit normal to the ice } \\
\text { front }\end{array}$ \\
\hline$p$ & Pressure $(\mathrm{Pa})$ \\
\hline$\rho$ & Ice density $\left(\mathrm{kg} \mathrm{m}^{-3}\right)$ \\
\hline $\bar{\rho}$ & Vertically averaged ice density $\left(\mathrm{kg} \mathrm{m}^{-3}\right)$ \\
\hline$\rho_{w}$ & Sea-water density $\left(\mathrm{kg} \mathrm{m}^{-3}\right)$ \\
\hline$\sigma_{|\mathbf{U}|}$ & Surface-velocity uncertainty $\left(\mathrm{ms}^{-1}\right)$ \\
\hline $\mathbf{T}=2 \nu \dot{\mathbf{e}}-p \mathbf{I}$ & Stress tensor $(\mathrm{Pa})$ \\
\hline$T(z)$ & Temperature profile $(\mathrm{K})$ \\
\hline $\mathbf{u}=(u, v)$ & Model horizontal velocity vector $\left(\mathrm{m} \mathrm{s}^{-1}\right)$ \\
\hline U & Observed velocity vector $\left(\mathrm{m} \mathrm{s}^{-1}\right)$ \\
\hline$x, y$ & Horizontal coordinates $(\mathrm{m})$ \\
\hline & Performance index (non-dimensional) \\
\hline & Vertical coordinate $(\mathrm{m})$ \\
\hline$z_{s}=\left(1-\frac{\bar{\rho}}{\rho_{u}}\right) h$ & Surface elevation (m) \\
\hline
\end{tabular}

\section{TYPICAL MODEL EQUATIONS}

To illustrate the testing package, we compared five iceshelf models (referred to by their city of origin and by the initials of their creator: Bremerhavenl (PH), Bremerhaven2 (JD), Chicagol (DRM), Chicago2 (CLH) and Grenoble (VR and CR)) using the Ross Ice Shelf modelling data base. All models except one (Bremerhaven2) are based on the following simplified, or reduced, stress-equilibrium equations.

$$
\begin{gathered}
\frac{\partial}{\partial x}\left(2 \nu h\left(2 \frac{\partial u}{\partial x}+\frac{\partial v}{\partial y}\right)\right)+\frac{\partial}{\partial y}\left(\nu h\left(\frac{\partial u}{\partial y}+\frac{\partial v}{\partial x}\right)\right) \\
-\rho g h \frac{\partial z_{s}}{\partial x}=0
\end{gathered}
$$

and

$$
\begin{gathered}
\frac{\partial}{\partial y}\left(2 \nu h\left(2 \frac{\partial v}{\partial y}+\frac{\partial u}{\partial x}\right)\right)+\frac{\partial}{\partial x}\left(\nu h\left(\frac{\partial u}{\partial y}+\frac{\partial v}{\partial x}\right)\right) \\
-\rho g h \frac{\partial z_{s}}{\partial y}=0
\end{gathered}
$$

where variables are defined in the notation list. The equations on which Bremerhaven2 is based differ from the above equations in that the ice thickness $h$ does not appear on either side of the equations and horizontal viscosity gradients $(\partial \nu / \partial x$ and $\partial \nu / \partial y)$ are not accounted for. The principal simplification embodied by all models is that horizontal flow is depth-independent (e.g. Sanderson and Doake, 1979). The validity of this assumption is contingent on the condition that $[H] /[L] \ll 1$ where $[H]$ and $[L]$ are characteristic vertical and horizontal distance scales, respectively (e.g. Morland, 1987; Morland and Zainuddin, 1987).

Boundary conditions needed to solve Equations (1) and (2) consist of kinematic (velocity specified) conditions at ice-shelf/inland ice boundaries and dynamic (pressure of sea water specified) conditions at the seaward ice front. After Morland (1987; see also Morland and Zainuddin (1987)), the boundary condition at the seaward ice front is idealized by applying a depth-integrated sea-water pressure force along a contour in the horizontal plane that follows the real ice front. In essence, the ice-front boundary condition disregards three-dimensional effects expected within the neighborhood of the ice front.

$$
\int_{\frac{-\rho h}{\rho_{w}}}^{\left(1-\frac{\rho}{\rho_{w}}\right) h} \mathbf{T} \cdot \mathbf{n} d z=\frac{-\rho_{w} g}{2}\left(\frac{\rho}{\rho_{w}} h\right)^{2} \mathbf{n},
$$

where $\mathbf{n}$ is the outward-pointing unit normal to the icefront contour in the horizontal plane.

Equations (1) and (2) use an effective viscosity $\nu$ to embody Glen's flow law. The definition of $\nu$ involves a temperature dependent rate constant $\bar{B}$ and a flow-law exponent $n$ :

$$
\nu=\frac{\bar{B}}{2\left[\left(\frac{\partial u}{\partial x}\right)^{2}+\left(\frac{\partial v}{\partial y}\right)^{2}+\frac{1}{4}\left(\frac{\partial u}{\partial y}+\frac{\partial v}{\partial x}\right)^{2}+\frac{\partial u}{\partial x} \frac{\partial v}{\partial y}\right]^{n-1 / 2 n}} .
$$

The flow-law rate constant $\bar{B}$ represents a depthaveraged value of the flow-law rate constant which can vary considerably over the Ross Ice Shelf as a result of temperature and density variation (e.g. Thomas and MacAyeal, 1982; MacAyeal and Thomas, 1986).

\section{ROSS ICE SHELF DATABASE}

Geophysical and glaciological observations of the Ross Ice Shelf have been made since the early part of this century (e.g. Bentley, 1984). We compiled a data base of these observations primarily from measurements made during the Ross Ice Shelf Geophysical and Glaciological Survey, 1973-78 (RIGGS) and the Siple Coast Project 1983-90 (see f. Glaciol., 39(133)). These observations include ice thickness (Bentley and others, 1979; MacAyeal and others, 1987), sea-bed depth (Bentley and Jezek, 1982), horizontal surface velocity U (Thomas and MacAyeal, 1982; Thomas and others, 1984; MacAyeal and others, 1987), annual average surface $(10 \mathrm{~m})$ temperature (Thomas and others, 1984), accumulation rate (Thomas and others, 1984), and density/depth and temperature/depth profiles at selected locations (Kirchner and others, 1979; Thomas and MacAyeal, 1982). Ice-stream and glacier input velocity 
boundary conditions were compiled from MacAyeal and others (1987) and MacAyeal and Thomas (1986). Ice-shelf modellers may access this Ross Ice Shelf data base at the World Data Center for Glaciology A, Boulder, Colorado, U.S.A.

\section{NUMERIGAL DOMAIN}

Two standard numerical discretizations of a $465000 \mathrm{~km}^{2}$ area of the Ross Ice Shelf are provided in the test data base (Fig. 1). A regularly spaced $147 \times 111$ array of grid points is designed for finite-difference models. An irregular mesh of triangular elements is designed for
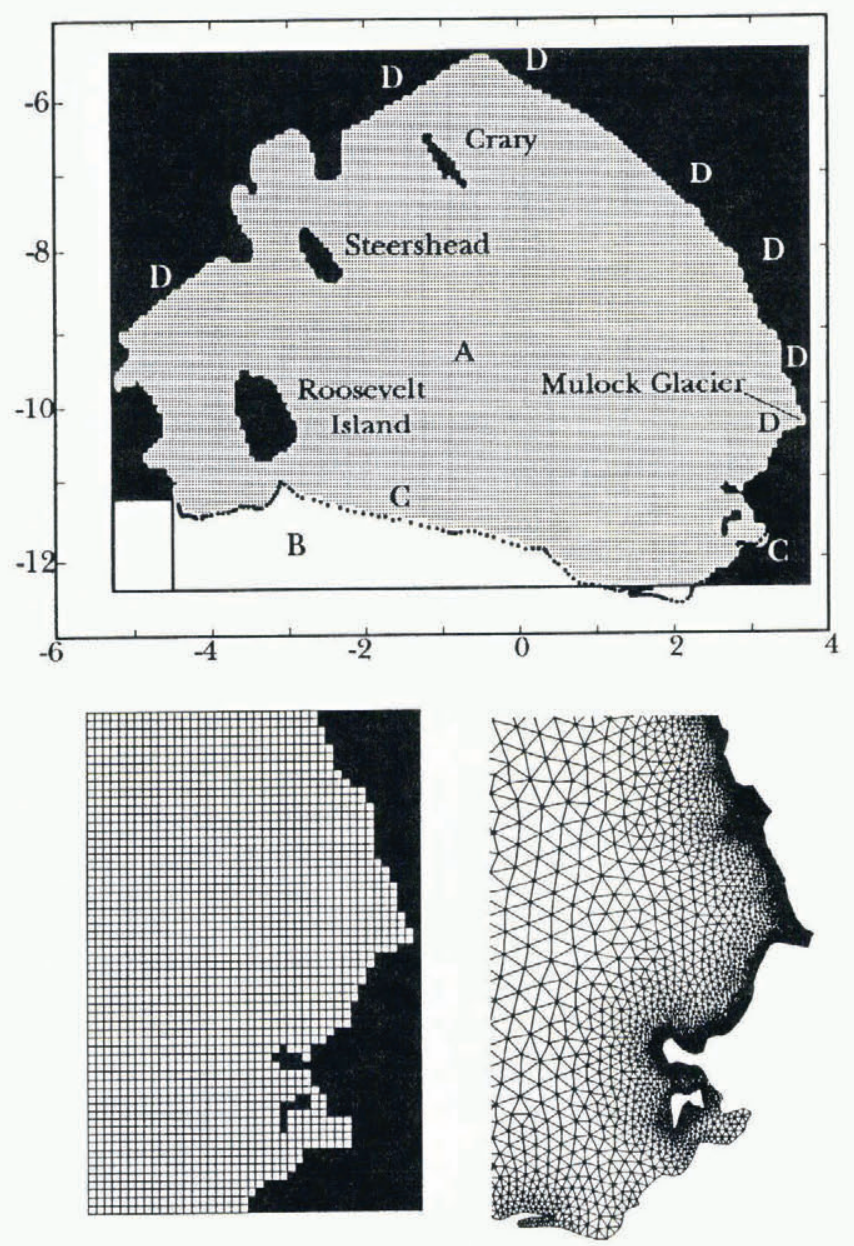

Fig. 1. Map of Ross Ice Shelf (upper panel) and finitedifference and finite-element discretizations of the Ross Ice Shelf near the Byrd Glacier outlet (lower panels). Coordinates are grid latitude and longitude as described by Bentley and others (1979). Region A (shaded) is the Ross Ice Shelf. Region B is the artificial $1 \mathrm{~m}$ thick ice-shelf region added to the finite-difference domain to create a rectilinear ice-front contour (note that it cuts off a part of the ice shelf near Ross Island). Label $C$ denotes the icefront contour in the finite-element domain. The part of the open ice front west of Ross Island (the McMurdo Ice Shelf) is treated as a closed boundary in the finitedifference model. Labels $D$ denote locations of outlet glaciers and ice streams where kinemalic boundary conditions are non-zero. Grid resolution is $6.822 \mathrm{~km}$ for the finite-difference domain. Mesh resolution for the finileelement domain varies from 0.5 to $20 \mathrm{~km}$. finite-element models. The spatial resolution of the finitedifference grid is $6.822 \mathrm{~km}$. The spatial resolution of the finite-element mesh varies from $0.5 \mathrm{~km}$ near boundaries to $20 \mathrm{~km}$ in central areas (Fig. 1). The finite-difference grid and the finite-element mesh were constructed to possess approximately the same number of grid points or nodes. For the finite-difference grid, there are 16317 grid points, of which 11067 are active. For the finite-element mesh, there are 16231 nodes and 30639 elements.)

Two options for treating the ice-front boundary are provided to accommodate finite-difference models which require simple, rectilinear geometry at boundaries where dynamic conditions are imposed. In both options, the ice shelf is artificially extended beyond the mid 1970s icefront position (see Fig. 1). In the Grenoble model, the ice thickness in this artificial region is reduced to $1 \mathrm{~m}$, while in the two Bremerhaven models the ice thickness is extrapolated from the existing ice shelf.

Test results presented below show that artificial extension of the ice shelf for finite-difference models generates little degradation of model performance within the confines of the real ice shelf. However, along the actual ice-front contour (separating the real and artificial parts of the ice shelf), finite-difference models cannot strictly enforce zero tangential stress. Thus, in circumstances where ice-front phenomena are of interest, finiteelement models may be preferable because of their capacity to handle curved geometry.

\section{MODEL PERFORMANCE ASSESSMENT}

Test results are assessed through comparison of the derived surface velocity and observations. At the simplest level, a single scalar measure of velocity misfit, $X^{2}$, is computed according to the formula

$$
X^{2}=\sum_{i=1}^{210} \frac{\left(\mathbf{u}_{i}-\mathbf{U}_{i}\right) \cdot\left(\mathbf{u}_{i}-\mathbf{U}_{i}\right)}{\sigma_{|\mathbf{U}|}^{2}} \delta_{i},
$$

where $\mathbf{u}$ is the model velocity, subscript $i$ identifies the RIGGS or Siple Coast Project station where a surface velocity is observed. The mask variable $\delta_{i}$ is 0 or 1 depending on whether station $i$ is within the numerical domain and whether there are valid velocity observations available for this station. The weighting variable $\sigma_{|\mathbf{U}|}$ is the assumed uncertainty of the observed velocity, which varies from \pm 5 to $\pm 30 \mathrm{~m} \mathrm{a}^{-1}$ among the RIGGS stations (Thomas and others, 1984). For the model intercomparison presented below, we adopt a uniform value of $\sigma_{|\mathbf{U}|}=30 \mathrm{~m} \mathrm{a}^{-1}$. The sum defining $X^{2}$ in Equation (5) is not divided by $N=210$, the number of stations where model and data can be compared, because we wish to identify $X^{2}$ with the $\chi^{2}$ variable used in statistical analysis of model/data mismatch (e.g. Menke, 1989, p. 32).

Other measures of model performance can be devised by the test-package user to emphasize model performance around specific physical features, such as ice rises, shear margins and the ice front, or to emphasize differences that occur in model intercomparison exercises. These measures are likely to take the form of contour, vector and tensor diagrams that can be constructed as diagnostics of the stress balance equations governing ice-shelf flow. 
Table 1. Model performance index, $X^{2}$ (non-dimensional)

\begin{tabular}{lrc}
\hline Model & $X^{2}$ & $\begin{array}{c}\text { Maximum velocity } \\
\mathrm{ma}^{1}\end{array}$ \\
\hline Bremerhaven 1 & 3605 & 1379 \\
Bremerhaven2 & 12518 & 1663 \\
Chicagol & 5114 & 1497 \\
Chicago2 & 5125 & 1497 \\
Grenoble & 5237 & 1508 \\
& & \\
\hline
\end{tabular}

\section{INTERCOMPARISON OF FIVE ICE-SHELF MODELS}

We intercompare five ice-shelf models introduced above. Three models, Grenoble, Bremerhavenl and Bremerhaven2, are based on the finite-difference method. Two models, Chicagol and Chicago2, are based on the finiteelement method. Grenoble is currently under development for future use in large-scale ice-sheet modelling (Rommelaere and Ritz, 1996). Bremerhavenl is associated with large-scale coupled dynamic/thermodynamic models of Antarctica (Huybrechts, 1990). Bremerhaven2 has been applied to the Ronne Filchner and Ekström Ice Shelves
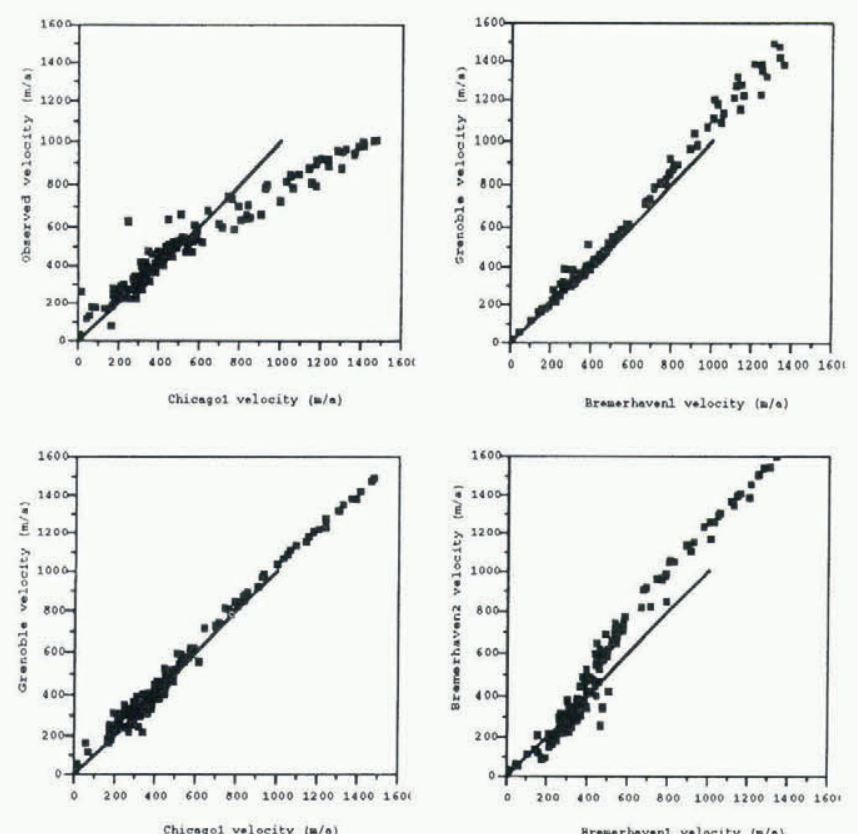

Fig. 2. Comparison between model-derived velocity magnitude (using Chicagol and a spatially uniform estimate of the depth-averaged flow-law rate constant) and observed velocity magnitude for 156 of the 210 RIGGS and Siple Coast Project stations contained within the finiteelement model domain (upper left). Misfit would be improved if the depth averaged flow-law rate constant were spatially variable. Comparison between model-derived velocily magnitude for Grenoble and Chicagol (lower left), Grenoble and Bremerhavenl (upper right) and Bremerhaven 2 and Bremerhaven1 (lower right) at the 156 stations.
(Determann, 1991). Chicagol is under development for studying ice-shelf/ice-stream interaction in Hudson Strait and the Labrador Sea off the North American continent during the glacial period. Chicago2 has been used to simulate the effects of recent iceberg calving off the Larsen Ice Shelf, Antarctica. None of these models has been specifically set up to study Ross Ice Shelf flow.

In this intercomparison, we use a spatially uniform value of $\bar{B}\left(1.9 \times 10^{8} \mathrm{~Pa} \mathrm{~s}^{\frac{1}{3}}\right)$. We adopt this simplification, because spatially varying values estimated by Thomas and MacAyeal (1982) have been found to yield a poor fit between model and observation. This inadequacy is due to the assumptions Thomas and MacAyeal made about the basal-melting rate and to their simplified, onedimensional heat-flow model used to determine internal ice-shelf temperatures. Despite the flow-law rate constant used in the test, the results of all five models are sufficiently close to the observed velocity that an intercomparison of the models appears justified.

The $X^{2}$ values associated with the five model runs are listed in Table 1. Figure 2 presents comparison plots of $\left|\mathbf{u}_{i}\right|$ vs $\left|\mathbf{U}_{i}\right|, i=1, \ldots, 210$, for the output of Chicagol. As explained above, agreement between observed and modelled velocity was not an intended outcome of the intercomparison test. Pairwise intercomparison of the $\left|\mathbf{u}_{i}\right|$, $i=1, \ldots, 210$, obtained by three of the models Chicago 2 is sufficiently close to Chicagol that its results need not be specially highlighted) are also shown in Figure 2. Models agree exactly when their respective values of $\left|\mathbf{u}_{i}\right|$, $i=1, \ldots, 210$, plot on a $45^{\circ}$ line in Figure 2. According to Figure 2, results of Grenoble and Chicagol agree for points at the high end of the velocity range; but, for points in the low-velocity range, there is considerable scatter (on the order of $\pm 100 \mathrm{ma}^{-1}$ ). Results of Grenoble and Bremerhaven 1 agree well in the low velocity range and are scattered off the $45^{\circ}$ line in the high-velocity range. Bremerhaven1 and Bremerhaven2 show considerable scatter off the $45^{\circ}$ line in all velocity ranges.

Figure 3 displays contour maps of $|\mathbf{u}|$ associated with Chicagol, Grenoble, Bremerhavenl and Bremerhaven2. All models produced a velocity pattern that is similar to that observed (Thomas and MacAyeal, 1982). The flow maximum is located at the ice front and strong shear layers are produced at the sides of ice rises and along coasts. In all models, the maximum velocity achieved at the ice front exceeds the observed flow by about $25 \%$. We expect this misfit to be corrected once better estimates of the flow-law rate constant are available.

Differences between the models (Figs 2 and 3) are apparent. First, the effect of model-equation differences between Bremerhaven2 and the other models (eliminating $h$ from both sides of Equations (1) and (2), and disregarding $\partial \nu / \partial x$ and $\partial \nu / \partial y$ terms) is nicely demonstrated by comparing panels $\mathrm{G}$ and $\mathrm{H}$ of Figure 3 with the other panels. The main effect of the model-equation differences is to uncouple velocity gradients from thickness gradients. This results in a weaker velocity gradient close to the grounding line and a stronger velocity gradient in the relatively flat area downstream of Crary Ice Rise in the Bremerhaven2 results compared to the other model results.

A second, and perhaps major, difference between models arises because of differences in boundary condi- 

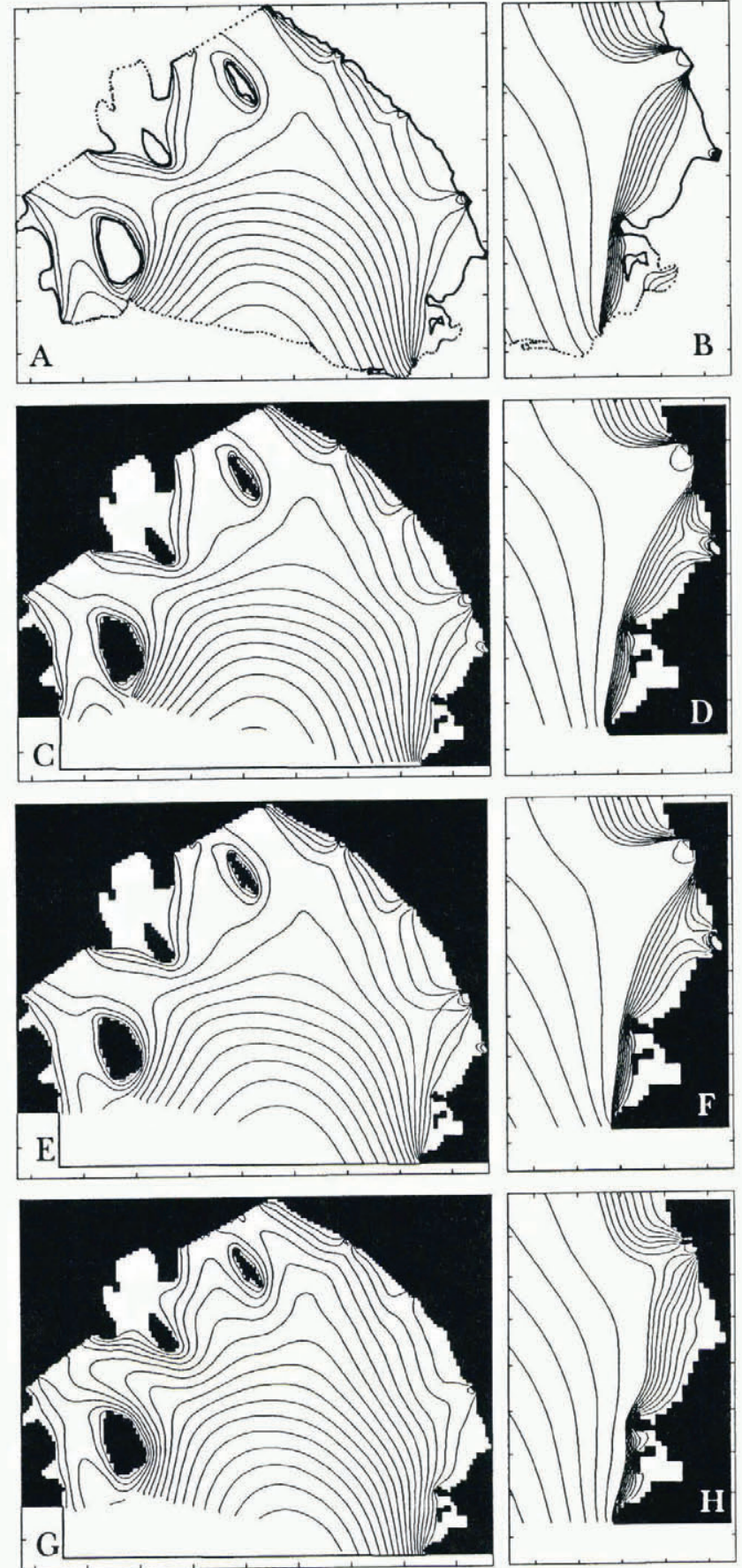

Fig. 3. Model velocity magnitude for Chicagol (panels A and $B$ ), Grenoble (panels $C$ and D), Bremerhaven1 (panels $E$ and $F$ ) and Bremerhaven2 (panels $G$ and $H$ ). Contour interval for panels $A, C, E$ and $G$ is $100 \mathrm{ma}^{-1}$, and for panels $B, D, F$ and $H$ is $25 m a^{-1}$ up to $200 \mathrm{ma}^{-1}$ and is $200 \mathrm{ma}^{-1}$ thereafter.

tions specified at the ice front. In models Chicagol and Chicago2, the finite-element method is ideally suited to treat curved ice-front boundary contours. The normal and tangential components of the boundary condition presented in Equation (3) are thus readily satisfied along the actual ice-front boundary by both models; and this, perhaps, is why the results of the two Chicago models are virtually identical.

In the finite-difference models, Grenoble and Bremerhavenl, the exact pressure balance is specified in the direction normal to the ice front (Equation (3)). In both models, the tangential velocity component is determined by the dynamic condition $\partial v / \partial x=-\partial u / \partial y$, where $v$ is the tangential velocity, $u$ is the normal velocity, $x$ is the coordinate directed perpendicular to the ice front and $y$ is the coordinate parallel to the ice front.

The difference between finite-difference models Grenoble, Bremerhaven 1 and Bremerhaven2 is the adoption of a $1 \mathrm{~m}$ thick artificial ice-shelf extension in the Grenoble model, and an ice-shelf extension with extrapolated thickness in the Bremerhavenl and Bremerhaven2 models. In the case of the Grenoble model, small thickness in the artificial ice-shelf extension makes the solution less sensitive to the exact prescription of the boundary condition. This explains why the results of the Grenoble model are almost the same as those of the finite-element models (Chicagol and Chicago2), which are presumed to satisfy the ice-front boundary conditions most readily along an irregular geometry.

The Bremerhaven2 model has a boundary condition for the normal velocity component associated with a freely expanding ice shelf in the normal direction only. Here, the transverse-velocity component has a zero gradient in the normal direction. These boundary conditions are the primary cause of the high ice-shelf velocities in the Bremerhaven 2 model compared to all the other models.

One surprise resulting from the model intercomparison is that difference in spatial resolution between finiteelement and finite-difference domains does not appear to be significant in determining large scale flow patterns. This suggests that the numerical efficiency associated with finitedifference methods over finite-element methods would be a leading advantage in designing ice-shelf models to treat large-scale flow. However, subtle differences between finite-element and finite-difference models can be seen in several small-scale features where spatial resolution has an influence on the fidelity of the numerical domain to the natural geometry. In panels B and D of Figure 3, comparing results from the Chicagol and Grenoble models, for example, ice velocity dowstream of the Mulock Glacier outlet in the Chicagol simulation is dramatically less than that in the Grenoble simulation. This difference is due to the fact that the finite-element mesh reproduces a narrower and extended glacier outlet channel than that reproduced by the finite difference grid. Apparently, the outflow of Mulock Glacier meets greater resistance in the long, narrow finite-element representation than in the more open finite-difference representation of the same iceshelf geometry. Regardless of which model results are more accurate, the difference displayed by the Mulock Glacier outlet comparison suggests that models based on finiteelement and finite-difference methods may have important differences in applications to regional-scale problems of complex geometry.

\section{CONGLUSION}

The test package presented here offers several benefits to potential ice-shelf model developers. First, it offers a chance to catch coding mistakes. Secondly, developers can periodically recheck their code against the observed flow of the Ross Ice Shelf after making improvements in 
model physics. Thirdly, differences between various numerical algorithms and their suitability for specific purposes can be assessed using a standard, controlled test problem. In our experience, all three benefits were realized in performing the intercomparison of five iceshelf models. We learned that finite-difference and finiteelement methods perform equally well in large-scale applications typical in ice and climate research. The finite-element method, however, appears to have an advantage in applications where complex, regional scale phenomena are of interest and where the ice-front boundary condition must be applied rigorously. We, additionally, learned that treatment of ice-front boundary conditions is the major factor in determining differences between ice-shelf model results in our standardized test.

\section{ACKNOWLEDGEMENTS}

We thank the EISMINT Steering Committee and the European Science Foundation for the student travel grant which allowed $\mathrm{V}$. Rommelaere to study at The University of Chicago. Support for D.R.M and C.L.H was provided by the U.S. National Science Foundation (N.S.F) under grants OPP 9218078 and OPP 9321457. P. Huybrechts is on leave with the Belgian National Fund for Scientific Research (NFWO).

\section{REFERENCES}

Bentley, C. R. 1984. The Ross Ice Shelf Geophysical and Glaciological Survey (RIGGS): introduction and summary of measurements performed. Antarct. Res. Ser., 42, 1-20.
Bentley, C. R. and K. C. Jezek. 1981. RISS, RISP and RIGGS: postIGY glaciological investigations of the Ross Ice Shelf in the U.S. programme. F. R. Soc. N.Z., 11 (4), 355-372.

Bentley, C. R., J. W. Clough, K. C. Jezek and S. Shabtaie. 1979. Icethickness patterns and the dynamics of the Ross Ice Shelf, Antarctica. 7. Glaciol., $24(90), 287-294$.

Determann, J. 1991. Numerical modeling of ice-shelf dynamics. Antarct. Sci., 3(2), 187-195.

Huybrechts, P. 1990. A 3-D model for the Antarctic ice sheet: a sensitivity study on the glacial-interglacial contrast. Climate Dyn., $5(2), 7992$.

Kirchner, J. F., C. R. Bentley and J. D. Robertson. 1979. Lateral density differences from seismic measurements at a site on the Ross Ice Shelf, Antarctica. f. Glaciol., 24(90), 309-312.

MacAyeal, D. R. and R.H. Thomas. 1986. The effects of basal melting on the present flow of the Ross Ice Shelf, Antarctica. 7 . Glaciol., $32(110), 72-86$.

MacAyeal, D. R., R. A. Bindschadler, S. Shabtaie, S. Stephenson and C. R. Bentley. 1987. Force, mass, and energy budgets of the Crary Ice Rise complex, Antarctica. f. Glaciol., 33(114), 218-230. [Correction in J. Glaciol., 35 (119), 151-152.].

Menke, W. 1989. Geophysical data analysis: discrete inverse theory. Revised edition. New York, Academic Press. [International Geophysics Series 45.]

Morland, L. W. 1987. Unconfined ice-shelf flow, In Van der Veen, C.J. and J. Oerlemans, eds. Dynamics of the West Antarctic ice sheet. Dordrecht, Kluwer Academic Publishers, 99-116.

Morland, L. W. and R. Zainuddin. 1987. Plane and radial ice-shelf flow with prescribed temperature profile. In Van der Veen, C. J. and J. Oerlemans, eds. Dynamics of the West Antarctic ice sheet. Dordrecht, etc., Kluwer Academic Publishers, 117-140.

Rommelaere, V. and C. Ritz. 1996. A thermomechanical model for iceshelf flow. Ann. Glaciol., 23.

Sanderson, T.J.O. and C. S. M. Doake. 1979. Is vertical shear in an ice shelf negligible? f. Glaciol., 22 87), 285-292.

Thomas, R. H. and D. R. MacAyeal. 1982. Derived characteristics of the Ross Ice Shelf, Antarctica. f. Glaciol., 28(100), 397-412.

Thomas, R. H., D. R. MacAyeal, D. H. Eilers and D. R. Gaylord. 1984. Glaciological studies on the Ross Ice Shelf, Antarctica, 1973-1978. Antarcl. Res. Ser., 42, 21-53. 